compone del tejido esplénico absolutamente normal, que incluye pulpa roja y sinusoides.

Ante el diagnóstico exploratorio se aconseja obtener una muestra del tejido urgente para que el patólogo lo certifique pudiendo así realizar una exéresis parcial de la masa, preservando el teste sobre todo en varones jóvenes.

Como anécdota, hay autores, como Patel, que aconsejan la búsqueda del tejido esplénico ectópico cuando se requiera una esplenectomía, suponiendo una alta frecuencia de esta entidad en forma asintomática, dado que al ser un tejido normal, aunque ectópico, los remanentes serían funcionalmente normales, pudiendo recidivar los síntomas derivados del hiperesplenismo.

El interés clínico de la «fusión esplenogonadal» radica, además de en su baja frecuencia, en que la mayoría son diagnosticadas como tumoración intraescrotal que obliga a cirugía y a orquiectomía en muchas ocasiones, pudiendo esta evitarse si existiera la sospecha previa, ya que la mera existencia del tejido esplénico normal en el escroto no constituye ningún tipo de problema para el paciente. Asimismo, hay que tener presente que el tejido esplénico accesorio y ectópico puede participar de aquellos procesos que afecten al bazo provocando esplenismo, como en parotiditis, leucemias, mononucleosis, incluso malaria. De esta manera, los restos esplénicos se manifestarían aumentando de tamaño a nivel escrotal.

B I B L I O G R A F Í A

1. De la Cruz A, Sánchez-López MJ, Adot JM, Sánchez-Cañizares T. Síndrome de la fusión esplenogonadal. Patología. 1990; 23:67.
2. Montes J, Tagle R, Navarro M, Iriarte C, Barría C. Fusión esplenogonadal. Reporte de 1 caso. Rev Chil Urol. 2005;70:75.

3. Prada A, Vázquez JL, Montero M, Muguerza R, Rodríguez Costa A. Bazo ectópico supernumerario intraescrotal: fusión esplenogonadal discontinua. Anales Pediatría. 2006;64:277.

4. Chen SL, Kao YL, Sun HS, Lin WL. Splenogonadal fusion. J Formos Med Assoc. 2008;107:892-5.

5. Pommer G. Verwachung die linken dryptorchischen Hondens und Nebenhodens mit der Milz in einer Missgeburt mit zahireichen Bildungsdefecten. Ber D Naturn-ned. 1887/89;19: 144.

6. Knorr P, Borden T. Splenogonadal fusion. Urology. 1994;44:136.

7. Petrik P. Spleen in the scrotum. Amer J Surg Path. 1988;12:414.

8. Llarena Ibarguren R, Añibarro Laca E, Pérez-Irezabal Pindado JC, Ibáñez Calle MT. Fusión esplenogonadal. Arch Esp Urol. 2008;61:445-8.

9. Trias Puig-Sureda I, Orsola los de Santos A, Raventós Busquets CX, Español Quintilla I, Bucar Terrades S. Fusión esplenogonadal. Presentación de un caso. Actas Urol Esp. 2007;31: 559-61.

10. Putschar W, Manion W. Splenic gonadal fusion. Am J Surg Pathol. 1956;32:15.

M. Álvarez Maestro ${ }^{\mathrm{a}, *}$, J. López-Tello $^{\mathrm{a}}$, P. Domínguez Franjo ${ }^{\mathrm{b}}$, E. Ríos González ${ }^{a}$ y L. Martínez-Piñeiro ${ }^{a}$

${ }^{a}$ Servicio de Urología, Hospital Infanta Sofía, Madrid, España

${ }^{\mathrm{b}}$ Servicio de Anatomía Patológica, Hospital Infanta Sofía, Madrid, España

*Autor para correspondencia.

Correo electrónico: malvarezmaestro@hotmail.com

(M. Álvarez Maestro).

\title{
Recidiva tumoral en sustitución vesical ortotópica. A propósito de dos casos y revisión de la literatura médica
}

\section{Tumor relapse in orthotopic bladder replacement. A report of two cases and literature review}

\section{Sr. Director:}

Los tumores vesicales tienen como característica bien conocida su tendencia a la recurrencia a lo largo de todo el urotelio. La mayor parte de las recidivas se producen en la misma vejiga y sólo un 2-3\% lo harán en la vía urinaria superior ${ }^{1}$. La recidiva en sustituciones vesicales intestinales es un fenómeno excepcional y poco conocido.

Se habían descrito con anterioridad adenocarcinomas desarrollados en derivaciones urinarias colónicas con relativa frecuencia como consecuencia de la initación de la mucosa intestinal en contacto con la orina. Las recidivas de tumores de urotelio en las derivaciones intestinales son menos frecuentes que las anteriores y se producen como consecuencia de una diseminación local o bien a distancia de un tumor que ya existía previamente ${ }^{2}$.

Entre 1975 y agosto de 2009 se han realizado en nuestro departamento 498 derivaciones urinarias tras la realización de una cistectomía radical. A lo largo de este período, hemos hallado dos casos de recidiva de carcinoma urotelial en neovejiga ortotópica.

El primer caso es un paciente de 71 años con antecedentes de tumor de urotelio T1G3 y carcinoma in situ recidivante tratado con RTU vesicales múltiples e instilaciones endovesicales con BCG. Al evidenciar recurrencia de la enfermedad tras la inmunoterapia, se le indicó tratamiento quirúrgico mediante cistovesiculoprostatectomía radical y se realizó una sustitución ortotópica tipo Camey II. El diagnóstico anatomopatológico fue 


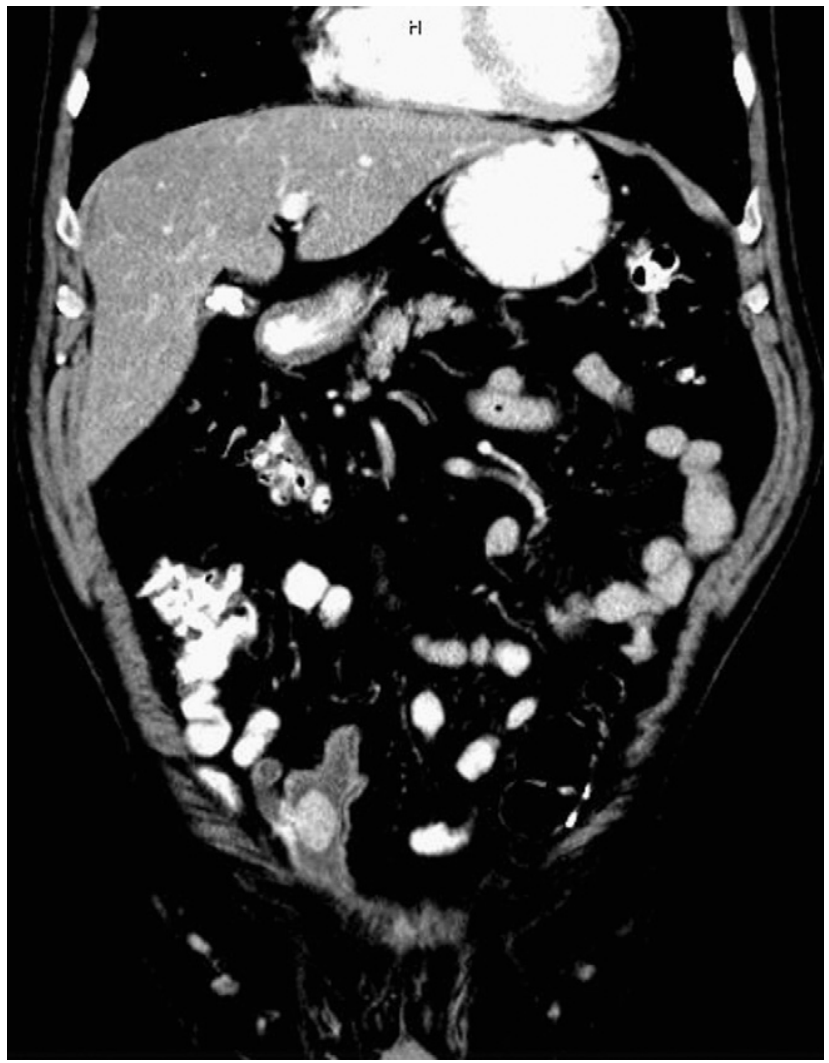

Figura 1 - Tomografía computarizada abdominal en el que se evidencia formación pediculada en el interior de la neovejiga.

de carcinoma in situ con afectación extensa de la vejiga. Acudió a consulta 8 años después refiriendo hematuria macroscópica. Se le realizó TC, donde se visualizó una tumoración en la vejiga ortotópica en la pared anterolateral derecha con crecimiento desde la anastomosis del uréter derecho (fig. 1). Realizamos RTU de la tumoración, reflejando el estudio histológico un carcinoma de células transicionales infiltrante de alto grado. Posteriormente, se le realizó una cistectomía parcial con exéresis de la zona donde se encontraba la recidiva tumoral próxima al uréter distal derecho con posterior reimplante de este. No se encontraron restos de enfermedad en el análisis de la pieza. Al año y tres meses de la intervención, el paciente se encuentra asintomático y sin evidencia de afectación neoplásica.

El segundo caso es un paciente de 57 años sometido a cistectomía radical y sustitución vesical ortotópica (Camey II) con diagnóstico de tumor urotelial pT3a, G3. A los siete años se le practicó una nefroureterectomía izquierda por recidiva a nivel de la pelvis. A los dos años, en la TC de control se apreció una lesión ocupante de espacio en el interior de la neovejiga (fig. 2). Se realizó cistoscopia con toma de biopsia de la lesión con diagnóstico de tumor de urotelio bien diferenciado. Posteriormente se le realizó cistectomía parcial de la neovejiga y exéresis del muñón ureteral izquierdo. La anatomía patológica reveló una recidiva de tumor urotelial que infiltraba el músculo liso intestinal. Se realizó tratamiento adyuvante con quimioterapia y radioterapia sobre la vejiga ileal y las áreas de drenaje linfático pélvicas y retroperitoneales. El paciente falleció 6 años después de la cistectomía parcial sin evidencia de enfermedad tumoral.

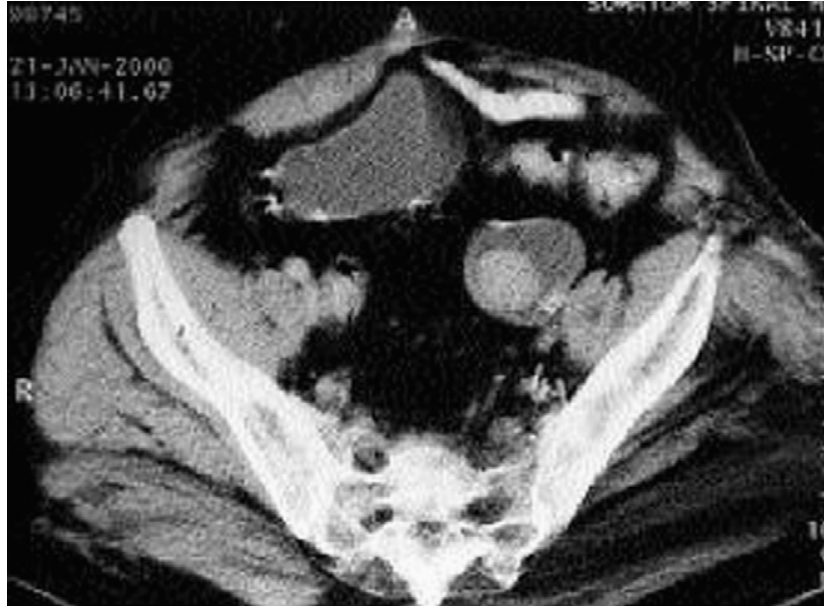

Figura 2 - Corte transversal de la tomografía computarizada en el que se aprecia una tumoración en la sustitución ortotópica.

La recurrencia en una derivación urinaria es un fenómeno raro y poco descrito ${ }^{3}$. En una revisión del Memorial Sloan Kettering Center en 1.100 anastomosis ureterointestinales, ningún caso de recidiva en el reservorio fue descubierto ${ }^{4}$. Se habían descrito con anterioridad adenocarcinomas desarrollados en derivaciones urinarias con relativa frecuencia, sobre todo en derivaciones urinarias a colon. Algunas revisiones hablan de un $25 \%$ de pacientes con adenocarcinoma 20 años después de la derivación urinaria colónica y de un 0,5\% en la ileal $^{5}$. En estos casos se origina un tumor de novo de estirpe intestinal, consecuencia de las diferentes interacciones físicas y químicas producidas en el reservorio. Sin embargo, la aparición de un nuevo tumor de urotelio en la mucosa colónica es un fenómeno menos descrito que demuestra la capacidad de las células tumorales vesicales de implantarse no solo en el urotelio, sino también en otras mucosas ${ }^{6}$.

En nuestro conocimiento sólo hay 19 casos de recidivas en derivaciones ileales descritos en la literatura médica. De estos casos, 4 fueron en vejigas ortotópicas y los otros 15 fueron derivaciones ileales. El lugar de recurrencia en 12 de ellos fue la anastomosis ureteroileal. En 5 casos la recurrencia fue en el reservorio y en una fue en el estoma. En estos últimos 6 casos, la recidiva estaba en lugares no adyacentes al urotelio, lo cual mostraría que los tumores vesicales pueden invadir epitelios no uroteliales.

Otro dato característico fue que 13 casos presentaron recurrencia concomitante en el tracto urinario superior. Algunos autores mantienen que el hecho de que meses antes de la recidiva se practicase una nefroureterectomía puede ser la causa de la implantación o siembra durante la cirugía ${ }^{7}$ y afirman que cuando se produce una recurrencia en el tracto urinario superior después de una cistectomía hay que tener en cuenta el riesgo de recidiva en la neovejiga de cara al seguimiento del paciente ${ }^{8}$. Otros estudios destacan el carácter multifocal de los tumores uroteliales y su tendencia intrínseca a recidivar. En este caso, el origen de la recurrencia en la derivación ileal sería una recidiva del tumor de urotelio a nivel del uréter distal que crecería desde la anastomosis ureteroileal invadiendo posteriormente el reservorio. 
Los 6 casos antes citados de recidiva en lugares no adyacentes a la anastomosis ureteroileal apoyan la teoría de la implantación, mientras que los 12 casos con recidiva a nivel de la anastomosis (incluidos nuestros 2 casos) reafirman la teoría de la carcinogénesis multicéntrica y hacen que ésta sea la causa más frecuente de recidiva de tumor urotelial a nivel de una derivación urinaria descrita en la literatura médica.

Clínicamente, pueden aparecer con un diverso abanico de síntomas, como tenesmo y dolor pélvico, siendo la hematuria la forma de presentación más frecuente. En otras ocasiones, pueden aparecer en un paciente asintomático en el seno de una revisión, diagnosticándose por pruebas de imagen.

El hecho de que las recurrencias en tumores uroteliales sean multifocales hace mandatario un estudio de extensión amplio. En la actualidad, la TC es el método de elección, pues no sólo caracteriza a la perfección la lesión en el interior de la derivación con todo el árbol urológico, sino que además nos descubre la afectación tumoral a distancia. La ileostografía retrógrada se planteaba como la prueba más adecuada para valorar la recidiva en la derivación ileal en los casos más antiguos descritos, combinándose con citologías urinarias ${ }^{9}$.

La ileoscopia es útil, como demuestran algunos autores, pues no sólo permite localizar la lesión en el interior de la derivación, sino que además nos permite realizar biopsias y optar por un tratamiento más conservador en un grupo seleccionado de pacientes como lo es la resección endoscópica. Esto era especialmente útil en los pacientes con derivaciones colónicas, en los que con más frecuencia había que diferenciar el origen intestinal del urotelial de la tumoración ${ }^{10}$.

Se han descrito RTU paliativas, cistectomías parciales y nefroureterectomías como tratamientos iniciales. Si la recidiva se produce a nivel de la anastomosis, es importante incluir un margen del íleon en la resección. En los casos en los que se demuestre o exista alto riesgo de enfermedad a distancia, la quimioterapia y la radioterapia adyuvante tienen su utilidad ${ }^{3}$.

Como conclusión podemos decir que la recurrencia de un tumor urotelial en una derivación urinaria es un fenómeno poco frecuente, pero que siempre debe ser sospechado, sobre todo cuando el paciente presenta hematuria, signo princeps y forma más habitual de manifestación inicial en los casos publicados en la literatura médica.
B I B L I O G R A F Í A

1. Herr IW. Tumor progression and survival of patients with high grade, noninvasive papillary (TaG3) bladder tumors: 15-years outcome. J Urol. 2000;163:60-2.

2. Ide H, Kikuchi E, Shinoda K, Mukai M, Murai M. Carcinoma in situ developing in an ileal neobladder. Urology. 2007;69 576.e9-11.

3. Sánchez Zalabardo D, López Ferrandis J, Arocena García-Tapia $\mathrm{J}$, et al. Recurrent urothelial tumor in orthotopic neobladder. Actas Urol Esp. 2001;25:600-2.

4. Grabstald H. Carcinoma of ileal bladder stoma. J Urol. 1974;112:332-4.

5. Frese R, Doehn C, Baumgartel M, et al. Carcinoid tumor in an ileal neobladder. J Urol. 2001;165:522-3.

6. Herawi M, Leppert JT, Thomas GV, De Kernion JB, Epstein JI. Implants of noninvasive papillary urothelial carcinoma in peritoneum and ileocolonic neobladder: Support for "seed and soil" hypothesis of bladder recurrence. Urology. 2006;67:746-50.

7. Curran FT, Fuggle WJ. Transitional cell carcinoma in an ileal conduit. Postgrad Med J. 1986;62:769-71.

8. Shioji Y, Morita T, Tokue A. Transitional cell carcinoma in the ileal conduit following radical cystectomy and nephroureterectomy. Scand J Urol Nephrol. 2001;35:416-7.

9. Soloway MS, Myers Jr GH, Burdick JF, et al. Ileal conduit exfoliative cytology in the diagnosis of recurrent cancer. J Urol. 1972;107:835.15-9.15 O.G. Banigo, J.

10. Celma Doménech A, Tremps Velásquez E, Planas Morin J, Bestard Vallejo J, Mir Marisma C, Morote Robles J. Transitional cell carcinoma relapse in uretero-ileal conduit after radical cystectomy. Actas Urol Esp. 2008;32:642-4.

J.F. Barba Abad*, E. Tolosa Eizaguirre, A. Rincón Mayans y J. Berian Polo

Departamento de Urología, Clínica Universidad de Navarra, Navarra, España

*Autor para correspondencia.

Correo electrónico: javiferbar@hotmail.com (J.F. Barba Abad).

\section{Metástasis peneana de carcinoma epidermoide de esófago Penile metastasis of esophageal scamous cell carcinoma}

\section{Sr. Editor:}

Le remito un caso de metástasis peneana de carcinoma esofágico localizada en el cuerpo esponjoso. Las neoplasias de pene son una patología infrecuente y de incidencia variable según la población ${ }^{1}$. De ellas, las metástasis a nivel del pene representan un escaso porcentaje ${ }^{2,3} \mathrm{y}$, cuando se presentan, son en su mayoría de origen pélvico
(75\%), mientras que el resto son de origen extrapélvico, principalmente el pulmón y el riñón ${ }^{4}$. Su aparición representa un estadio avanzado de la enfermedad y suelen manifestarse como efecto masa o priapismo maligno ${ }^{5}$. El gold standard de diagnóstico es la resonancia magnética $(\mathrm{RM})^{6}$. Existen múltiples opciones de tratamiento, desde la abstención terapéutica, la cirugía y, en determinados casos, la quimioterapia ${ }^{7,8}$. 